\title{
Can the Montreal Cognitive Assessment Predict Discharge Destination in a Stroke Population in the Hospital?
}

Citation for published version (APA):

Geubbels, H. J. B., Nusselein, B. A. M., van Heugten, C. M., Valentijn, S. A. M., \& Rasquin, S. M. C. (2015). Can the Montreal Cognitive Assessment Predict Discharge Destination in a Stroke Population in the Hospital? Journal of Stroke \& Cerebrovascular Diseases, 24(5), 1094-1099.

https://doi.org/10.1016/j.jstrokecerebrovasdis.2015.01.034

Document status and date:

Published: 01/01/2015

DOI:

10.1016/j.jstrokecerebrovasdis.2015.01.034

Document Version:

Publisher's PDF, also known as Version of record

\section{Document license:}

Taverne

Please check the document version of this publication:

- A submitted manuscript is the version of the article upon submission and before peer-review. There can be important differences between the submitted version and the official published version of record.

People interested in the research are advised to contact the author for the final version of the publication, or visit the DOI to the publisher's website.

- The final author version and the galley proof are versions of the publication after peer review.

- The final published version features the final layout of the paper including the volume, issue and page numbers.

Link to publication

\footnotetext{
General rights rights.

- You may freely distribute the URL identifying the publication in the public portal. please follow below link for the End User Agreement:

www.umlib.nl/taverne-license

Take down policy

If you believe that this document breaches copyright please contact us at:

repository@maastrichtuniversity.nl

providing details and we will investigate your claim.
}

Copyright and moral rights for the publications made accessible in the public portal are retained by the authors and/or other copyright owners and it is a condition of accessing publications that users recognise and abide by the legal requirements associated with these

- Users may download and print one copy of any publication from the public portal for the purpose of private study or research.

- You may not further distribute the material or use it for any profit-making activity or commercial gain

If the publication is distributed under the terms of Article $25 \mathrm{fa}$ of the Dutch Copyright Act, indicated by the "Taverne" license above, 


\title{
Can the Montreal Cognitive Assessment Predict Discharge Destination in a Stroke Population in the Hospital?
}

\author{
Heleen J. B. Geubbels, MSc, ${ }^{*}$ Bram A. M. Nusselein, MSc, + \\ Caroline M. van Heugten, MSc, PhD, $\ddagger$ Susanne A. M. Valentijn, MSc, PhD, + \\ and Sascha M. C. Rasquin, MSc, $\operatorname{PhD} \S \|$
}

\begin{abstract}
Background: To decide on an appropriate discharge destination for stroke survivors from hospital, factors such as activities of daily living and age are often taken into account as predictors. Cognition has been found to support the decision whether to send a patient home or to a dependent living situation. The Montreal Cognitive Assessment (MOCA) has been proven to be a suitable cognitive screening instrument in the acute phase after stroke. However, its predictive value in the determination of discharge destination is unknown. The aim of the present study was to examine whether cognitive functioning, as measured with the MOCA, in the acute phase after stroke could predict discharge destination. Methods: The study involved 211 patients with a first-ever cerebral stroke within the first week after stroke. Demographic and stroke-specific data, cognitive functioning (MOCA), and level of functional disability (Barthel Index [BI]) were collected. Multivariate logistic regression analyses were used to predict discharge destination (dependent versus independent living situation). Results: Both age $(\mathrm{B}=-.05 ; P<.01)$ and $\mathrm{BI}$ score $(\mathrm{B}=.33 ; P<.001)$ were found to be significantly related to discharge destination with explained variance of $43 \%$. Adding MOCA score as a predictor variable to the model resulted in a nonsignificant improvement of the model, explaining $44 \%$ of the variance. Conclusions: Cognitive functioning, as measured by a single screening instrument such as the MOCA, in the acute phase after stroke is not predictive for discharge destination. Key Words: Stroke-cognitive screening-stroke assessmentneuropsychology.
\end{abstract}

(C) 2015 by National Stroke Association

From the *Department of Neuropsychology and Psychopharmacology, Faculty of Psychology and Neuroscience, Maastricht University; +Department of Medical Psychology, Catharina Hospital, Eindhoven; ‡Department of Neuropsychology and Psychopharmacology, School for Mental Health and Neuroscience, Maastricht University, Maastricht, The Netherlands; §Department of Neurology, Rehabilitation Centre Adelante, Hoensbroek, The Netherlands; and ||Department of Rehabilitation Medicine, School CAPHRI, Maastricht University, Maastricht, The Netherlands.

Received December 18, 2014; accepted January 30, 2015.

There are no disclosures.

There are no sources of funding.

Address correspondence to Caroline M. van Heugten, PhD, Department of Psychiatry and Neuropsychology, Maastricht University, FHML, PO Box 616, Maastricht 6200 MD, The Netherlands.

E-mail: c.vanheugten@maastrichtuniversity.nl.

$1052-3057 / \$$ - see front matter

(C) 2015 by National Stroke Association

http:/ / dx.doi.org/10.1016/j.jstrokecerebrovasdis.2015.01.034
Stroke is a major cause of disability. In addition to physical impairment, approximately $50 \%-78 \%$ of stroke patients experience cognitive impairments. ${ }^{1-3}$ The most frequently reported cognitive impairments involve problems in memory, orientation, language, attention, executive functioning, and arithmetic and slowness of information processing. ${ }^{1-4}$ These "invisible" stroke sequels can have far-reaching consequences for patients and their environment with respect to daily life activities, social activities, ${ }^{5}$ sense of well-being, ${ }^{6}$ and return to work. ${ }^{7}$ Because of the frequency and impact of cognitive impairments, standardized cognitive assessment should be conducted within the first weeks after stroke. Taking into account that (extensive) neuropsychological testing is time-consuming, screening procedures involving all 
cognitive domains with sufficient sensitivity and easy to use are called for.

To decide on an appropriate discharge destination from hospital, several factors are taken into account, such as dependence in activities of daily living (ADL) and age. ${ }^{8}$ Another important factor that contributes to the discharge destination decision is cognitive functioning, as measured by a neuropsychological examination. ${ }^{9}$ Van der Zwaluw et al (2010) found that cognitive screening, including the Mini-Mental State Examination (MMSE), Cognitive Screening Test, and Clock Drawing Test, in the acute phase after stroke contributes to the prediction of a suitable discharge destination. However, the MMSE alone was not a significant predictor for discharge destination and was thus not suitable for prediction. This may be because of the fact that the MMSE does not cover all cognitive domains and was originally developed for dementia screening. ${ }^{9,10}$ Hence, the MMSE does not appear to be the optimal means to examine cognitive function and predict outcome in the acute phase after stroke.

The Montreal Cognitive Assessment (MOCA) may be considered a more suitable alternative. This screening instrument is found to be feasible in screening for cognitive impairment in stroke patients ${ }^{11}$; the MOCA corrects for education ${ }^{12}$; the MOCA is more sensitive than the MMSE in screening for cognitive deficits ${ }^{10,13-15}$; and it has a higher internal reliability and less of a ceiling effect than the MMSE. ${ }^{15}$ More importantly, the MOCA is superior to the MMSE in screening for cognitive problems in executive functioning, attention, recall, and visual construction. ${ }^{10}$ Nonetheless, the predictive value of the MOCA has not yet been investigated.

The aim of the present study, therefore, was to examine to what extent cognitive functioning as measured by the MOCA, administered within 1 week after stroke, is able to predict discharge destination. Because of the fact that functional disability and age influences long-term independence in $\mathrm{ADL}^{8,16}$ these factors were taken into the account as well.

\section{Methods}

\section{Patients}

Stroke patients who were referred to the stroke unit of a hospital in the south of the Netherlands between February 2010 and September 2011 were eligible for participation in the study. Only those patients who were present at the stroke unit on Tuesdays when standardized cognitive screening was conducted were included in the present study. Stroke patients meeting the following criteria were included in the present study: a first-ever stroke, based on the medical record, age 40 years or older (to avoid atypical stroke), eligible for testing (ie, no severe aphasia, impaired consciousness, extreme fatigue, or motor problems based on clinical judgment). Patients who were not able to speak the Dutch language were excluded. The study was conducted according to the Code of Conduct for Medical Research of the Council of the Dutch Federation of Medical Scientific Societies. At this hospital, all patients are informed that their files can be used anonymously for research purposes, unless they object. A review procedure by a medical ethics committee is not needed for use of anonymous routinely collected data.

\section{Procedure}

Each patient was screened at the stroke unit (at bedside) by a neuropsychologist using the MOCA within a week after admission to the hospital as part of the standard diagnostic procedure. Four days after admission to the hospital, a nurse established the level of functional disability using the Barthel Index (BI). Demographic and injury-related information was obtained from the patients' medical record (including age, gender, level of education, type of stroke, and date of admission). The multidisciplinary stroke team, consisting of a neurologist, physiotherapist, occupational therapist, speech therapist, nurse, and if the patient was vigorous and younger than 65 years, a rehabilitation doctor, determined a suitable discharge destination for each patient.

\section{Measures}

The neuropsychological screening consisted of the MOCA, which can identify mild cognitive impairments in stroke survivors in the acute phase after stroke. ${ }^{17}$ It assesses various cognitive functions, including memory, visuospatial ability, executive functioning, attention, concentration, language, and orientation. The MOCA can be administered in 10 minutes. Participants are given 1 additional point if they had less than 12 years of education. The maximum score is 30 points. If an individual achieves a score of less than 26 points, the individual is considered to be cognitively impaired.

The BI score was used to measure the level of functional disability by indicating the ability to perform certain activities in daily life (eg, dressing, external care, and going up and down stairs). ${ }^{18}$ The BI consists of 10 items, with a maximum score of 20 , implying complete independence. The minimum score is 0 , indicating that a patient is totally dependent.

Discharge destination was determined by a multidisciplinary team.

\section{Statistical Analyses}

Patient and test characteristics were described on the basis of descriptive statistics.

To investigate whether cognitive functioning in the acute phase after stroke could be used to predict discharge destination, a similar method was used as in van der Zwaluw et al (2010). We dichotomized discharge destination 
Table 1. Patient characteristics

\begin{tabular}{|c|c|c|c|}
\hline Characteristics & $\begin{array}{l}\text { All patients } \\
(\mathrm{n}=211)\end{array}$ & $\begin{array}{l}\text { Independent discharge } \\
\text { destination }(\mathrm{n}=68)\end{array}$ & $\begin{array}{l}\text { Dependent discharge } \\
\text { destination }(\mathrm{n}=143)\end{array}$ \\
\hline Sex, M/F, n & $110 / 101$ & $40 / 28$ & $70 / 73$ \\
\hline Age, y, mean $\pm \mathrm{SD}$ (range) & $70.6 \pm 11.8(41-92)$ & $66.0 \pm 10.7(45-85)$ & $72.8 \pm 11.6(41-92)^{*}$ \\
\hline \multicolumn{4}{|l|}{ Education } \\
\hline Low/medium/high & 23/98/42 & $4 / 33 / 15$ & $19 / 65 / 27$ \\
\hline \multicolumn{4}{|l|}{ Stroke type } \\
\hline Ischemic/hemorrhagic & $184 / 21$ & $63 / 2$ & $121 / 19^{*}$ \\
\hline Days between stroke and cognitive screening & $5.1 \pm 4.9(1-36)$ & $4.3 \pm 3.1(1-19)$ & $5.5 \pm 5.6(1-36)$ \\
\hline MOCA score, mean \pm SD (range) & $19.8 \pm 6.2(3-30)$ & $23.1 \pm 4.5(7-30)$ & $18.3 \pm 6.2(3-29)^{*}$ \\
\hline BI score 4 days after admission, mean $\pm \mathrm{SD}$ (range) & $15.0 \pm 5.6(0-20)$ & $18.7 \pm 2.6(10-20)$ & $13.2 \pm 5.7(0-20)^{*}$ \\
\hline
\end{tabular}

Abbreviations: BI, Barthel Index; F, female; M, male; MOCA, Montreal Cognitive Assessment; SD, standard deviation.

* Mean values that are marked with an asterisk indicate a significant difference $(P<.05)$ between the independent and dependent group.

into 1 (home; independent, including all patients returning to their homes, not needing any care) and 0 (dependent, including patients who were discharged home with an outpatient rehabilitation facility, plus all patients who were discharged to a destination outside the home, such as a rehabilitation center or nursing home) to create 2 groups that could be compared. Normality was checked and subsequently Mann-Whitney $U$ tests were used as an alternative for independent sample $t$ tests to determine whether there were differences between the independent and dependent discharge destination groups. When significant differences between groups were found, these factors were controlled for by adding them in the multivariate logistic regression analysis. Pearson correlation coefficients were calculated to determine the associations between demographic variables (including sex, age, education level, type of stroke, days between stroke and screening, and discharge destination) and the screening tests (including MOCA score and BI score). Sequential multivariate logistic regression analysis was run with MOCA score, age and BI score serving as predictor variable s (ie, independent variables) and discharge destination (dependent and independent) as the outcome variable (ie, dependent variable). Two models were analyzed: the first model included age and BI score, as these factors influence the discharge decision process. ${ }^{8,16}$ The second model included age and BI score, as well as MOCA score. This model was used to identify the additional predictive value of the MOCA. Variables showing group differences were also added in the analyses. The $\alpha$ level was set at $P$ less than .05. Statistical analyses were performed with the Statistical Package for Social Sciences SPSS, version 17.0 (IBM SPSS 17.0, SPSS Inc., Chicago, IL).

\section{Results}

\section{Patients}

A total of 392 patients, who were referred to the stroke unit of the Catharina Hospital between February 2010 and
September 2011 and who were present on Tuesdays, were considered for a cognitive screening.

Twenty-seven patients passed away before the cognitive screening was conducted. Excluding patients who were aged 40 years or younger $(n=2)$, and patients who were not $(n=76)$ or not completely $(n=37)$ eligible for screening on the basis of the inclusion criteria, resulted in a sample of 250 patients. Patients who were not able to speak the Dutch language and those who refused to cooperate were not included in the study $(n=5)$. As 32 patients had an unknown BI score and 2 patients had an unknown discharge destination, this resulted in a final study sample of 211 patients who were included in this study. Table 1 describes the patient characteristics.

Patients with a dependent discharge destination were significantly older $(\mathrm{U}=3178.50, P<.001)$, required more help with ADL as determined by the BI scores $(\mathrm{U}=1819.00, P<.001)$, had lower MOCA scores $(\mathrm{U}=2627.50, P<.001)$, and were more likely to have a hemorrhagic stroke $(\mathrm{U}=4072.50, P<.05)$ compared with patients who were discharged to an independent destination.

When a MOCA score cutoff value of less than 26 was applied, 47 patients $(69.1 \%)$ with an independent discharge destination and 124 patients $(86.7 \%)$ with a dependent discharge destination were classified as cognitively impaired (Table 2). This resulted in a total number of 171 patients $(81.0 \%)$ being classified as cognitively impaired.

\section{Correlations}

Table 3 shows that older patients had significantly lower MOCA scores $(\mathrm{r}=-.37 ; P<.001)$, as well as patients with a low educational level $(r=.29 ; P<.001)$, patients with a hemorrhagic stroke $(\mathrm{r}=.18 ; P<.05)$, and patients with a low BI score $(\mathrm{r}=.47 ; P<.001)$. The more days between the stroke and administration of the MOCA, the lower the MOCA score $(r=-.24 ; P<.01)$. 
Table 2. Number of cognitively impaired and unimpaired patients

\begin{tabular}{lccc}
\hline Cognitively impaired/unimpaired & $\begin{array}{c}\text { All patients } \\
(\mathrm{n}=211)\end{array}$ & $\begin{array}{c}\text { Independent discharge } \\
\text { destination }(\mathrm{n}=68)\end{array}$ & $\begin{array}{c}\text { Dependent discharge } \\
\text { destination }(\mathrm{n}=143)\end{array}$ \\
\hline Number of cognitively impaired patients $(\%)$ & $171(81.0)$ & $47(69.1)$ & $124(86.7)$ \\
Number of cognitively unimpaired patients $(\%)$ & $40(19.0)$ & $21(30.9)$ & $19(13.3)$ \\
\hline
\end{tabular}

Patients with a higher MOCA score were more likely to be discharged to an independent destination $(\mathrm{r}=.37$; $P<$.001). The significant correlation between education and $\operatorname{sex}(\mathrm{r}=-.18 ; P<.05)$ indicates that male patients tended to have a higher educational level. Age and BI correlated significantly $(\mathrm{r}=-.17 ; P<.05)$, as well as age and discharge destination $(\mathrm{r}=-.27 ; P<.001)$, meaning that younger patients had higher BI scores and an independent discharge destination. Patients with a higher educational level had significantly higher BI scores ( $\mathrm{r}=$ $.20 ; P<.05)$. Patients with an ischemic stroke $(\mathrm{r}=.16$; $P<.05)$ and patients with higher BI scores $(\mathrm{r}=.46$; $P<.001)$ were more likely to be discharged home.

\section{Logistic Regression Analyses}

Because of the finding that both groups differed with respect to type of stroke, this factor was controlled for by adding it as a predictor variable in the logistic regression analyses.

The model including age, BI score, and type of stroke showed good model fit $\left(\chi^{2}(3)=74.2 ; P<.001\right.$; Table 4$)$. According to Nagelkerke's $R^{2}, 43 \%$ of the variability was explained by this model. Both age $(\mathrm{B}=-.05$; $P<.01)$ and $\mathrm{BI}$ score $(\mathrm{B}=.33 ; P<.001)$ were found to be significantly related to discharge destination; patients with a lower age and patients with a higher BI score were more likely to be discharged home. However, type of stroke did not significantly contribute in the prediction of discharge destination.

Adding MOCA score as a predictor variable to the model resulted in a nonsignificant improvement of the model $\left(\chi^{2}(4)=76.3 ; P>.05\right)$. MOCA score, combined with the variables age, BI score, and type of stroke explained $44 \%$ of the variance. However, although age $(\mathrm{B}=-.04 ; P<.05)$ and $\mathrm{BI}$ score $(\mathrm{B}=.31 ; P<.001)$ were found to be significant predictors of discharge destination, type of stroke and MOCA score were not.

\section{Discussion}

From the results of this study it can be concluded that the MOCA does not contribute to the prediction of discharge destination of stroke patients in the first week after stroke.

Age and physical disability contributed to the prediction of discharge destination, which was also found in previous studies. ${ }^{1,8,16}$ Although we found that cognition as measured by the MOCA was not predictive for discharge destination, van der Zwaluw et al (2010) showed that a cognitive screening in the acute phase after stroke does contribute to the discharge destination process. Although this contribution was rather small, the difference between the present study and the study of van der Zwaluw et al (2010) can be explained by the fact that van der Zwaluw et al (2010) applied a combination of the MMSE, Cognitive Screening Test, and Clock Drawing Test to measure cognition, whereas we used the MOCA, a single screening instrument. However, both studies show that a particular cognitive screening, such as the MOCA or the MMSE, was not predictive for discharge destination. From this, we can conclude that cognition, measured by a single cognitive screening in the acute phase after stroke is not a suitable

Table 3. Correlations between the MOCA and demographic and stroke-related characteristics

\begin{tabular}{|c|c|c|c|c|c|c|c|}
\hline Variables & $\begin{array}{c}\text { MOCA } \\
\text { score }\end{array}$ & Sex & Age & Education & $\begin{array}{c}\text { Type } \\
\text { of stroke }\end{array}$ & $\begin{array}{c}\text { Days between } \\
\text { stroke and } \\
\text { screening }\end{array}$ & BI score \\
\hline \multicolumn{8}{|l|}{ MOCA score } \\
\hline Sex & -.03 & & & & & & \\
\hline Age, y & $-.37 * * *$ & .12 & & & & & \\
\hline Education & $.29 * * *$ & $-.18^{*}$ & -.10 & & & & \\
\hline Type of stroke & $.18^{*}$ & -.03 & -.01 & .07 & & & \\
\hline Days between stroke and screening & $-.24 * *$ & -.04 & -.04 & -.05 & .11 & & \\
\hline BI score & $.47 * * *$ & -.02 & $-.17 *$ & $.20 *$ & -.13 & -.12 & \\
\hline Discharge destination & $.37 * * *$ & -.09 & $-.27 * * *$ & .11 & $-.16^{*}$ & -.12 & $.46^{* * *}$ \\
\hline
\end{tabular}

Abbreviations: BI, Barthel Index; MOCA, Montreal Cognitive Assessment. $* P<.05, * * P<.01, * * * P<.001$. 
Table 4. Results from logistic regression analysis

\begin{tabular}{lcccc}
\hline $\begin{array}{l}\text { Regression } \\
\text { Models }\end{array}$ & $\chi^{2}$ & Df & $R^{2}$ & Bagelkerke's \\
\hline Model 1 & 74.2 & 3 & .43 & \\
Age, y & & & & $-.05^{* *}$ \\
BI score & & & & $.33^{* * *}$ \\
Type of stroke & & & & -1.50 \\
Model 2 & 76.3 & 4 & .44 & \\
Age, y & & & & $-.04^{*}$ \\
BI score & & & & $.31^{* * *}$ \\
Type of stroke & & & & .06 \\
MOCA score & & & & .42 \\
\hline
\end{tabular}

Abbreviations: BI, Barthel Index; MOCA, Montreal Cognitive Assessment.

$* P<.05, * * P<.01, * * * P<.001$.

manner to predict discharge destination. This may be because of the fact that the MMSE and the MOCA both do not cover all cognitive domains, such as processing speed, ${ }^{19}$ which is frequently affected in stroke patients (Rasquin et al, 2004)..$^{20}$ Future studies should investigate the predictive value of a single cognitive screening, measuring all relevant cognitive domains for long-term outcome in the prediction of discharge destination.

We found that $81 \%$ of the stroke patients were cognitively impaired: $69 \%$ of the patients with an independent discharge destination and $87 \%$ of the patients with a dependent discharge destination. The number of cognitively impaired patients in our study is rather large, compared with earlier studies, ${ }^{11,19}$ demonstrating that $65 \%-66 \%$ of the stroke patients were found to have a score below the cutoff value on the MOCA. However, in the studies of Cumming et al (2011) and Pendlebury et al (2012) the patients were screened 3 and 6 months after stroke, respectively, whereas the patients in the present study were screened within 1 week after stroke. As many stroke survivors show considerable recovery over the succeeding months, ${ }^{21-23}$ it is conceivable that the patients in the studies of Cumming et al (2011) and Pendlebury et al (2012) were in a further phase of recovery. However, other studies showed that 35\%-55\% of the patients in the acute phase after stroke were cognitively impaired, ${ }^{1,8}$ confirming that the number of cognitively impaired patients in our study is large. As the latter studies did not apply the MOCA, this finding may be explained by the fact that the MOCA is very sensitive in screening for cognitive deficits.

The dependent and independent discharge destination groups differed with respect to age and BI score, which corresponds to previous studies. ${ }^{1,8}$ However, both groups also differed in type of stroke, which contradicts the finding in the study of van der Zwaluw et al (2010). Patients with a hemorrhagic lesion were found to score lower on a functional independence measure on admission compared with patients with an ischemic lesion. ${ }^{24}$ As the present study showed, functional outcome in stroke patients is an important predictor for discharge destination. This is in line with the finding that the number of patients with a hemorrhagic lesion is proportionally larger in the dependent group.

In clinical practice, other factors than cognition are taken into account when deciding on discharge destination. Living status (ie, dependent or independent, presence of a caregiver, marital status, and membership of societies and clubs) before the incidence of a stroke seems to be an important predictor for discharge destination. ${ }^{25-29}$ We did not take these factors into account, which is a limitation of the present study. Moreover, a large proportion of the variability was not accounted for which indicates the possible influence of other factors. Future studies should investigate the predictive value of living status before the incidence of a stroke by adding these variables into the analysis.

\section{Conclusion}

Cognition, as measured by a single screening instrument such as the MOCA, is not predictive for discharge destination. On the one hand, future studies should investigate the predictive value of cognition using a more comprehensive screening tool when deciding about a suitable discharge destination. On the other hand, the predictive value of living situation before a stroke should be investigated more extensively when deciding whether a patient should be discharged to their home or to a dependent living situation.

Acknowledgments: The authors thank Tonnie van de Laar and Nelleke van Westering for helping us with the data collection.

\section{References}

1. Nys GM, van Zandvoort MJ, de Kort PL, et al. Cognitive disorders in acute stroke: prevalence and clinical determinants. Cerebrovasc Dis 2007;23:408-416.

2. Rasquin SM, Verhey FR, Lousberg R, et al. Cognitive performance after first ever stroke related to progression of vascular brain damage: a 2 year follow up CT scan study. J Neurol Neurosurg Psychiatry 2005;76:1075-1079.

3. Tatemichi TK, Desmond DW, Stern Y, et al. Cognitive impairment after stroke: frequency, patterns and relationship to functional abilities. J Neurol Neurosurg Psychiatry 1994;57:202-207.

4. Hochstenbach J, Mulder T, van Limbeek J, et al. Cognitive decline following stroke: a comprehensive study of cognitive decline following stroke. J Clin Exp Neuropsychol 1998;20:503-517.

5. Pedersen PM, Jorgensen HS, Nakavama H, et al. General cognitive function in acute stroke: the Copenhagen Stroke Study. J Neuro Rehab 1996;10:153-158.

6. Clarke P, Marshall V, Black SE, et al. Well-being after stroke in Canadian seniors: findings from the Canadian Study of Health and Ageing. Stroke 2002;33:1016-1022. 
7. Hofgren C, Bjorkdahl A, Esbjornsson E, et al. Recovery after stroke: cognition, ADL function and return to work. Acta Neurol Scand 2007;115:73-80.

8. Van der Zwaluw CS, Valentijn SA, Nieuwenhuijs-Mark R, et al. Cognitive functioning in the acute phase poststroke: a predictor of discharge destination? J Stroke Cerebrovasc Dis 2010;20:549-555.

9. Nys GM, van Zandvoort MJ, de Kort PL, et al. Restrictions of the Mini-Mental State Examination in acute stroke. Arch Clin Neuropsychol 2005;20:623-629.

10. Dong Y, Sharma VK, Chan BP, et al. The Montreal Cognitive Assessment (MOCA) is superior to the Mini-Mental State Examination (MMSE) for the detection of vascular cognitive impairment after acute stroke. J Neurol Sci 2010;299:15-18.

11. Cumming TB, Bernhardt J, Linden T. The Montreal Cognitive Assessment. Short cognitive evaluation in a large stroke trial. Stroke 2011;42:2642-2644.

12. Nazem S, Siderowf AD, Duda JE, et al. Montreal Cognitive Assessment performance in patient with Parkinson's disease with "normal" global cognition according to Mini-Mental State Examination score. J Am Geriatr Soc 2009;57:304-308.

13. Blackburn DJ, Bafadhel L, Randall M, et al. Cognitive screening in the acute stroke setting. Age Ageing 2013; 42:113-116.

14. MacKenzie G, Gould L, Ireland S, et al. Detecting cognitive impairment in clients with mild stroke or transient ischemic attack attending a stroke prevention clinic. Can J Neurosci Nurs 2011;33:47-50.

15. Toglia J, Fitzgerald KA, O'Dell MW, et al. The MiniMental State Examination and Montreal Cognitive Assessment in persons with mild subacute stroke: relationship to functional outcome. Arch Phys Med Rehabil 2011;92:792-798.

16. Schiemanck SK, Kwakkel G, Post MW, et al. Predicting long-term independency in activities of daily living after middle cerebral artery stroke: does information from MRI have added predictive value compared with clinical information? Stroke 2006;37:1050-1054.

17. Nasreddine ZS, Philips NA, Bédirian V, et al. The Montreal Cognitive Assessment, MOCA: a brief screening tool for mild cognitive impairment. J Am Geriatr Soc 2005;53:695-699.
18. Wolfe CD, Taub NA, Woodrow EJ, et al. Assessment of scaled of disability and handicap for stroke patients. Stroke 1991;22:1242-1244.

19. Pendlebury ST, Markwick A, de Jager CA, et al. Differences in cognitive profile between TIA, stroke and elderly memory research subjects: a comparison of the MMSE and MOCA. Cerebrovasc Dis 2012; 34:48-54.

20. Rasquin SM, Lodder J, Ponds RH, et al. Cognitive functioning after stroke: a one-year follow-up study. Dement Geriatr Cogn Disord 2004;18:138-144.

21. Bach-y-Rita P. Central nervous system lesions: sprouting and unmasking in rehabilitation. Arch Phys Med Rehabil 1981;62:413-417.

22. Skillbeck CE, Wade DT, Hewer RL, et al. Recovery after stroke. J Neurol Neurosurg Psychiatry 1983;46:5-8.

23. Wade DT, Wood VA, Hewer RL. Recovery of cognitive function soon after stroke: a study of visual neglect, attention span and verbal recall. J Neurol 1988;51: 10-13.

24. Ring H, Feder M, Schwarz J, et al. Functional measures of first-stroke rehabilitation inpatients: usefulness of the Functional Independence Measure total score with a clinical rationale. Arch Phys Med Rehabil 1997;78: 630-635.

25. Lezak MD, Howieson DB, Loring DW. Neuropsychological assessment. 4th ed. New York, NY: Oxford university Press 2004.

26. Massucci M, Perdon L, Agosti M, et al. Prognostic factors of activity limitation and discharge destination after stroke rehabilitation. Arch Phys Med Rehabil 2006;85: 963-970.

27. Meijer R, van Limbeek J, Kriek B, et al. Prognostic social factors in the subactute phase after a stroke for the discharge destination from the hospital stroke-unit. A systematic review of the literature. Disabil Rehabil 2004; 26:191-197.

28. Wee JY, Hopman WM. Stroke impairment predictors of discharge function, length of stay and discharge destination in stroke rehabilitation. Am J Phys Med Rehabil 2005; 84:604-612.

29. Ween JE, Mernoff ST, Alexander MP. Recovery rates after stroke and their impact on outcome prediction. Neurorehabil Neural Repair 2000;14:229-235. 